\title{
Study on the Transformation and Upgrading of Equipment Manufacturing Industry in Jiangsu from the Perspective of Global Value Chain
}

\author{
Rong Wang \\ College of Jincheng \\ Nanjing University of Aeronautics and Astronautics \\ Nanjing, Jiangsu, China 211156
}

\begin{abstract}
The equipment manufacturing industry, the "Master" of industry, is the strategic basic industry to provide various technical equipments for economic construction and national defense and security, the important symbol to measure the scientific and technological progress and comprehensive competitive power of the country and regions and the core element of manufacturing industry. Jiangsu is one of the most developed regions in economy of our country and one of the regions with the most rapid development of manufacturing industry. However, the division position of global value-chain in Jiangsu is still on the lower position. Especially in computer, electron, optics and other equipment manufacturing industry with higher technical grades, the lower position in Jiangsu is relatively obvious. The paper discusses the researches on transformation and upgrading of equipment manufacturing industry in Jiangsu from the perspective of global value chain and explores the approaches for transformation and upgrading of the equipment manufacturing industry in Jiangsu.
\end{abstract}

Keywords-global value chain; Jiangsu; equipment manufacturing industry; transformation and upgrading

\section{INTRODUCTION}

The equipment manufacturing industry is the core source power for the industry development of our country, is the strategic basic industry for the manufacturing industry development, is the main symbol to measure the competitiveness of our country and regions and is also the "Master" of manufacturing industry. The equipment manufacturing industry accounts for nearly $50 \%$ in the entire industry. To develop the industry requires the regions to develop equipment manufacturing industry first so as to drive the development of other industries.

\section{DEVELOPMENT STATUS AND POSITION OF EQUIPMENT MANUFACTURING INDUSTRY IN JIANGSU}

Jiangsu is one of the regions with the most developed manufacturing industry in our country and is the most important production base for the equipment manufacturing

Fund Project: Surface Program of Policy Guidance Plan (Soft Science Research) in Jiangsu Province in 2016 "Study on the Transformation and Upgrading of Equipment Manufacturing Industry in Jiangsu from the Perspective of Global Value Chain” (Program No.: BR2016051). industry and high-end equipment manufacturing industry of our country. Therefore, it is especially necessary to conduct intensive study on the equipment manufacturing industry in Jiangsu.

As one of the earliest industrial bases, Jiangsu Province occupies the dominating position in the industrial development in Jiangsu. Through the development of several decades, Jiangsu Province has formed the equipment manufacturing industry system with complete categories and higher technical level. And the equipment manufacturing industry has played important role in the economic development progress in Jiangsu. In recent years, with the relatively rapid development, the equipment manufacturing industry has become one of the major growth points of industrial economy in Jiangsu and has played strong promoting function for economic growth of Jiangsu. In 2014, there are 19,113 equipment manufactures in Jiangsu, accounting for $39.24 \%$ in the 48708 industry enterprises in Jiangsu Province; 5.3774 million employees, accounting for $47.04 \%$ in the 11.4305 million in Jiangsu Province; 4279.72 billion yuan of capital, accounting for $42.26 \%$ in the 5937.853 billion of Jiangsu Provinces. The comprehensive strength of Jiangsu equipment manufacturing industry is relatively strong in the whole country and the position of strong province in equipment manufacturing industry has been established.

With the continuous refining and deepening of the global value chains specialization, although the equipment manufacturing industry in Jiangsu has achieved rapid development and has been continuously deepening the integration degree in the global value chain, its position in the global value chain specialization is still relatively low. Especially for computer, electron, optics and other equipment manufacturing industry with higher technical grades, its position in the value chain is not ideal because the overhigh foreign additional value content makes it located in the lower link in global value chain.

The integrated value chain position of Jiangsu equipment manufacturing industry is on lower side. Thus, during the progress of transformation and upgrading, the equipment manufacturing industry should seize the favorable opportunity of industrial structure adjustment and transformation and 
upgrading, insist on the general principle of "making progress while working to keep performance stable" to comprehensively deepen reform and keep promoting the scientific and technological innovation and structure optimization, taking the quality improvement and beneficial results improvement as the central tasks to provide powerful support for the reasonable operation of macro-economy. Through improving the development and creative abilities, increasing the capital investment on technology, optimizing the internal structure of industry and coordinating the development among departments, the author believes that the equipment manufacturing industry in Jiangsu will break through the difficulties and make the global value chain used by Jiangsu so as to become the strong engine and acceleration for the realization of strong province of manufacturing from the big manufacturing province.

\section{CONSTRAINTS FOR THE TRANSFORMATION AND UPGRADING OF JIANGSU EQUIPMENT MANUFACTURING INDUSTRY FROM THE PERSPECTIVE OF GLOBAL VALUE CHAIN}

\section{A. Market Demands}

The changes of total demands and demand structures will lead to the changes of upgrading capacities of the regional equipment manufacturing industry while the influences on the industrial upgrading from changes of demand structures are more direct. The final products manufacturers in equipment manufacturing industry in Jiangsu are mostly the large enterprises possessing scale economic benefits. With the increase of final products demands and the improvement of regional supporting industries, those large enterprises will gradually abandon the integrative production mode and outsource the businesses of parts manufacturing etc but only reserve the links with high additional value; many supporting enterprises realize the business expansion through undertaking the core enterprises outsourcing link and get rid of the single parts manufacturing and gradually access to the market of lowend products. The flow of this production factor changes the proportion structure of industrial sectors and causes the changes of the industrial structure of regional equipment manufacturing industry and further leads to the change of industrial upgrading capacities.

\section{B. Human Capital}

The labor force is the most active and important factor in the three factors of productivity. Under the circumstance where other conditions remain unchanged, the low-quality labor force will be the obstacle for industrial structure to develop towards the higher stage; while the high-quality labor force with modern technology and cultural quality can accelerate the optimization and upgrading of industrial structure. Even though there are not abundant natural resources, capital and technological advantages, if only emphasizing on the investment on human capital, accelerating the human capital accumulation, effectively taking in and absorbing the advanced technologies of the world through technology import and using those technologies and international capitals to transform the traditional industries in Jiangsu, develop and cultivate high and new technology industries can promote the optimization of regional industrial structure and further promote the industrial upgrading. Therefore, the quality of human capitals is the important factor influencing the industrial upgrading.

\section{Influence from Foreign Capitals}

There are both sides of the foreign capital influence on industrial upgrading. The import of foreign capital brings new production processes and management methods which improves the production efficiency and also intensifies the competition of the market in Jiangsu. Local enterprises continuously improve the research and development abilities and complete the product quality and launch new products to compete with the foreign enterprise which increases the additional value in global value chain and optimizes the trade structure of products and promotes the industrial upgrading. Secondly, the large import of foreign capitals leads to the flow of production factors and brings with capitals technologies and other scarce factors as well as the beneficial marketing abilities which are favorable to the change of factor endowment structure and the transformation of comparative advantages of enterprises in Jiangsu. Finally, the foreign capitals import is to obtain more benefits. When the development of enterprises in Jiangsu is adverse to the benefits of foreign enterprises, those foreign transnational corporations may limit the development of enterprises in Jiangsu by adopting the methods of agreements, disinvestment or restrict the technological innovation from the upper or middle links so as to further control the whole value chain and reduce the additional value profits of the development of equipment manufacturing industry in Jiangsu which is adverse to industrial upgrading.

\section{Technology Effects}

1) Technology diffusion and absorption: Under the background of internationalized labor division and market integration, enterprises in each country all participate in the global value chain to complete the finished products together. There exists the mutual competition and cooperation among those enterprises. To better improve the product quality and the supplying efficiency of various suppliers, the leading suppliers will provide technical supports complying with quality to the lower suppliers for the fluent completion of product value chain. For example, to improve the product quality and supplying efficiency, the developed countries will transfer part of the technologies in the direct investment or directly assign experts for the technical guidance. During this progress, the equipment manufacturing industry in Jiangsu continuously gathers experiences and technologies and uses the effect of learning by doing to absorb and transform the technologies and promote the technological innovation of industry.

2) Enterprise technology innovation: The enterprise technology innovation activities are the source for upgrading of industrial structure of regional equipment manufacturing industry. The technological breakthrough brought by technological innovation improves the manufacturing techniques of products, improve the production technological contents and lead to the industrial structure upgrading through promoting the technical level of Jiangsu equipment manufacturing industry. As the core enterprises possessing 
resource superiority in the regional equipment manufacturing industry, it will be easier to make breakthrough in technological innovation. Due to the guiding role to other enterprises in this region, the technological innovation of core enterprises has more important driving effects on the technology upgrading in the whole region.

\section{E. Degree of Opening Up}

The influence of opening up degree on the industrial structure upgrading of equipment manufacturing industry is mainly manifested through the foreign direct investment and foreign trade. Provide with financial support for the industrial structure upgrading of equipment manufacturing industry through the import of foreign direct investment and rapidly promote the industrial structure upgrading process of Jiangsu equipment manufacturing industry through effects of technological spillovers and market demonstration etc. The foreign trade expands demands and stimulates economic growth through import and promotes the development of emerging industries and the industrial structure upgrading of equipment manufacturing industry through optimization of export structure. On the other hand, the foreign trade accelerates the industrial transfer of Jiangsu equipment manufacturing industry of developed countries. Through the import of foreign advanced equipment, techniques and technologies, Jiangsu equipment manufacturing industry promotes the improvement of techniques and technological process of equipment manufacturing departments and further promotes the transformation of traditional equipment manufacturing enterprises and the development of emerging equipment manufacturing enterprises so as to realize the optimization and upgrading of the industrial structure of Jiangsu equipment manufacturing industry.

\section{F. Government Policies}

The government policies have significant influence on the industrial upgrading including the laws and regulations and economic policies related to the scientific researches such as investment policies, financial policies and patent protection system etc. Through the formulation and implementation of strategic industry supportive policy, the government policies promote the regional equipment manufacturing industry to actively participate in the international division of labor, take full advantage of second-mover advantages, race to control the high-end link of value chain, drive the integrated transition of the value chain link of Jiangsu equipment manufacturing industry and finally realize the upgrading of industrial structure of Jiangsu equipment manufacturing industry.

\section{G. Development of Producer Services}

As the advanced production factor investment of equipment manufacturing industry, the production link with high-quality technical services built in the equipment manufacturing industry can not only reduce the production costs and provide specialized services for the equipment manufacturing enterprises in the industry through the improvement of skills; but also can be beneficial to establish the long-term and stable partnership of the two to save more transaction costs. At the same time, the completion of producer services under the industry chain can attract the customer resources of other industries. The "intermediary" service in the producer service can provide more opportunities of interdisciplinary development for the equipment manufacturing enterprises. Under the global value chain, the production is basically located in the lower link of value chain while the links such as design, research and development and the brand marketing etc which possess the high added-value are the upgrading objectives of equipment manufacturing industry. And most of the composition of the two-end links is the producer service.

\section{CONCLUSION}

The approaches for transformation and upgrading of Jiangsu equipment manufacturing industry from the perspective of global value chain are summarized as follow:

\section{A. Transformation toward Service-Oriented Manufacturing}

Due the low value added of equipment manufacturing industry, the equipment manufacturing can be transformed into the service-oriented manufacturing (the industrial form integrating with the product manufacturing and value-added services which emphasizes on the initiative and personalized services). The service-oriented manufacturing focuses on the value-added services during the product using process and maximizes its value, mutually provides the productive service and production of services, realizes the closer and closer farmout and creates higher added value through the service outsourcing. The extension of manufacturing value chain also can be realized through the initiative and personalized services of enterprises. In the top or lower links of manufacturing value chain, the manufacturing industry obtains specialized services from the specialized productive service departments while in the middle link of manufacturing value chain, the manufacturing enterprises are engaged in the specialized production such as production activities of services and create more value through the reasonable distribution of enterprise labor division on the different levels of manufacturing value chain.

\section{B. Accelerate the Development of Technology-Intensive Industries}

Transforming the traditional industries by high and new technologies is the important measure to improve the comprehensive strength of Jiangsu equipment manufacturing industry and also the only way to improve the quality and benefit of economic growth which can be started with the following aspects: firstly, accelerate to use the high and new technologies to transform the traditional industries and use the high and new technologies to transform the equipment of traditional industries and improve the level of technical equipment; secondly, develop and produce the high and newtechnology products and improve the scientific and technical contents and value added of products; thirdly, apply the computer technology to transform the traditional and out-dated enterprise management models and let the enterprise management of traditional industries step in the modern management and promote the industrial structure upgrading. 


\section{Formulate and Implement the Related Supportive Policies on Finance and Tax and Increase the Policy Support Degree}

Further increase the government $R \& D$ expenditure and policy support degree on Jiangsu high-end equipment manufacturing industries which has significant meaning for the further improvement of international competitiveness and industrial structure optimization and upgrading of high-end equipment manufacturing industries. According to the relevant policies and stipulations of the state and province, the enterprises which use the high and new technologies to transform the traditional industries and reach to the conditions of identification shall be positively identified and shall enjoy the preferential policies for new high-tech enterprises. Take full and good advantage of the preferential policies for high and new technology industrialization, encourage and support the enterprises to adopt the high and new technologies to transform the traditional industries. Take full advantage of the preferential policies such as national bonds for technological innovation, finance discount and the shares listing financing to increase the investment on transformation of traditional industries by using the high and new technologies.

\section{Improve the Industrial Structure Rationality}

Firstly, conduct the industrial upgrading on the basis of existing links of research and development and assembly. Emphasis on both the equipment manufacturing and technology research and development so as to avoid the industry hollowing only with high-end research and development links while without the processing and assembly links in the developed countries.

Secondly, depend on the industrial upgrading to realize the industrial structure rationality. The industrial upgrading of Jiangsu equipment manufacturing industry can be realized from the perspective of value chain. Put forth effort on the top of value chain, the investigation service on market positioning before the rapid development of production, design services during the research and development processes, talent training during the research and development cooperation and production process and the consultation services for laws, property right and management and the services for brands, logistics and export etc to introduce the human capital and knowledge capital to the services and production of Jiangsu equipment manufacturing industry.

Thirdly, In the over-all situation of supply-side reform, set out with the improvement of supplying quality of Jiangsu equipment manufacturing industry, use the method of reform to promote the structural adjustment, rectify the twisted factors allocation, expand the effective supply, improve the adaptation and flexibility of supply structure on changes in demand and improve the total factor productivity. At the same time, establish the effective connection mechanism of demand and supply, keep the communication channels for market information of equipment manufacturing industry unblocked avoid the unbalance of supply and demand caused by the delay or mistakes or omission of information.

\section{E. Put forth Efforts on the Cultivation of Professional Talents with High Quality}

When the equipment manufacturing industry is developing towards the high-grade, precision and advanced orientation, the cultivation of high-quality professional talents is becoming more and more important. The government and enterprises need to cooperate to complete the construction of macroenvironment and microenvironment when introducing human resources so as to attract core research personnel and administrative staff with international project background and encourage the cultivation of talents with strong practical operation. While the industries and enterprises mainly depending on the quantity of labor force need to be guided timely instead of being restricted to the development of lowend equipment manufacturing industry. The low-end equipment manufacturing industries usually possess the features of large quantity of labor force, low quality of labor force and low profit in the industry. This human resource structure needs to be adjusted timely instead of just emphasizing on the labor productivity but needing to connect the industry profits and high-quality talents to consider together.

\section{REFERENCES}

11] Lin Guijun, He Wu. Position of Chinese Equipment Manufacturing Industry in the Global Value Chain and Upgrading Tendency[J]. Journa of International Trade, 2015(4):3-15.

[2] Chen Aizhen, Zhong Guoqiang. Whether the International Trade of Chinese Equipment Manufacturing Industry Promotes Its Technological Development- Based on the Panel-data Analysis of DEA[J]. Economist, 2014(5):43-53

[3] Deng Xiangrong, Cao Hong. Approaches Choices for Industria Upgrading: Complying with or Deviating from the Comparative Advantage-Based on the Empirical Analysis on Product Spatial Structure[J]. China Industrial Economics, 2016(2):52-67.

[4] Wang Shaoyuan, Li Guopeng. Empirical Analysis on the Binary Marginal Effects of TBT on the Export of Chinese Manufacturing Enterprises-Based on the Two-Stage Gravity Model[J]. Macroeconomics, 2016(8):74-83.

[5] Tan Rongjuan. FDI Intensity and the Low-Carbon Transformation Development of equipment Manufacturing Industry in Pearl River Delta-Based on the Empirical Study on Input-Output and Panel-Data[J]. Journal of International Trade, 2012(2):81-91.

[6] Shang Xiaohu. Study on the Influence Factors of Technologica Innovation Performance of Chinese Equipment Manufacturing IndustryFrom the Empirical Analysis on Listed Companies[J]. Shanghai Journal of Economics, 2013(9): 71-79. 